\title{
Assessing Nigeria's Journey towards IFRS Adoption
}

\author{
Bello Usman Baba \\ Universiti Utara Malaysia, Malaysia \\ ammiya2011@yahoo.com
}

\begin{abstract}
Recently the global corporate financial reporting scene has experienced a tremendous transformation with an unprecedented number of countries and enterprises around the world adopting IFRS as a basis in preparing financial statements. In Nigeria, the journey towards adoption of IFRS started in December 2010 and thus an implementation roadmap was designed which was broken down into three phases. Based on the above affirmation, the study assesses the achievements recorded so far, challenges being encountered, and measure taken in order to ensure a smooth and successful implementation of the three phases. Hence, the study is predominantly based on review of various journals, research papers, newspaper articles, periodicals and other documentary materials of professional accounting bodies as well as conferences, seminars and workshop papers. Consequently, the study found that most publicly quoted companies listed on the Nigerian stock exchange (NSE) were still far behind in their implementation process. Thus, the reason for the delay is attributed to several factors which ranges from challenge with amendment of the existing tax laws, the level of awareness among various stakeholders, weak compliance and enforcement mechanisms, the education level and experience, insufficient technical capacity, inadequate planning on the part of companies' management as well as inadequate private sector participation. Accordingly, suggestions were made on how to forestall these challenges and ensure a smooth and successful implementation of the next phases.
\end{abstract}

\section{Keywords: Financial reporting, IFRD adoption, Nigeria}

\section{Introduction}

Lately the global corporate financial reporting scene has experienced a tremendous transformation with an unprecedented number of countries and enterprises around the world adopting International Financial Reporting Standards (IFRS) as a basis of preparing financial statements and therefore a means of narrowing the areas of differences in accounting practice as well as improving the comparability, quality and transparency of financial information across nations (UNCTAD, 2008). The road towards a common accounting standard dates back from 1973 when 16 professional accountancy bodies from Australia, United Kingdom, Canada, Mexico, Germany, Japan, United States, Netherlands and France decided to establish the International Accounting Standard Committee (IASC) with the aim of issuing a globally accepted standard which was referred to as International Accounting Standards (IAS). In 2001, the International Accounting Standard Committee (IASC) was restructured to form International Accounting Standard Board (IASB) with the responsibility of issuing IFRS. However, in 2001; IFRS gain popularity when the European Union (EU) requires all listed companies in its 17 member countries to adopt IFRS in preparing their consolidated accounts with effect from January 1, 2005. Similarly, China mandated its listed companies to adopt the IFRS in their financial reporting beginning from 2007, while Canada announced the abolition and replacement of its local GAAP with IFRS in 2011 (Larson \& Street, 2004).

Moreover, the growing acceptability of IFRS continued with the US Securities and Exchange Commission (SEC) removing the requirement for reconciliation of financial information to US GAAP. In effect, foreign companies were initially required to reconcile their financial reports to suit the US GAAP as a criterion to be listed in the US capital market, but from 2007, companies whose financial reports are prepared in conformity with the IFRS do not have to reconcile with the US GAAP. This development facilitates smooth listing of foreign companies in the US capital market (Epstein \& Jermakowicz, 2010). In Nigeria, the journey towards adoption of IFRS started in December 2010, following its approval by the Federal Executive Council, the Financial Reporting Council of Nigeria (FRCN) (previously known as Nigerian Accounting Standards Board (NASB)), designed an implementation roadmap for adoption of the standards which was broken down into three phases, the first of which is compliance by Banks and other significant public listed entities whom are expected to prepare their financial statement based on IFRS by 31 December, 2012. Phase two requires other public interest entities to adopt IFRS effective 31 
December, 2013 and the last phase which is phase three is adoption by Small and Medium Enterprises (SMEs') scheduled for 31 December, 2014.

Moreover, due to some challenges and difficulties such as low level of awareness, inadequate technical capacity among preparers and users of financial statements, weak enforcement mechanism, and inadequate capacity building etc., hampered the smooth implementation of the phase one; whereby few listed companies comply with the directive. Based on the aforementioned, this study assesses the achievements recorded so far, challenging encounters, and measure taken in order to ensure a smooth and successful implementation of the three phases. Thus, the rest of the paper is organized into four sections. The next section is on review of related literature, section three described the methodology, section four addresses issues of convergence, while section 5 carries conclusion.

\section{Literature Review}

The global convergence of accounting standards is attracting much attention in the academic and professional accounting literature (Prather-Kinsey, 2006). Thus, worldwide convergence of accounting standards is seen as an attempt to reduce accounting diversity across countries. Hence, the main objective of reducing accounting diversity is to ensure that all companies across the globe follow a single set of accounting standards especially with the recent increased globalization in international markets, international trade, cross border financial transactions and investment opportunities. Therefore, this had led to the adoption of IFRS as a basis of preparing and presenting accounting reports across several national borders. However, the adoption of IFRS is now becoming a trend across countries given the enormous advantages it provide countries and multinational companies (Tesfu, 2012). But despite the advantages in converging to IFRS, there are arguments for and against the adoption of the standards; some scholars argued for the adoption of IFRS while others are against the standards. Barth (2007) argued for adoption of IFRS, he specified that a single set of internationally accepted standards is expected to lower the cost of processing financial information and auditing to users of capital market, increase uniformity and comparability of financial statements across companies in different countries thereby easing the job of investment analysts, facilitate easy access to foreign investments as well as liberalization of capital markets. Similarly, Hali, Leuz and Wysocki (2010) also support the adoption of IFRS arguing that the adoption of IFRS is a means of lowering the cost of capital, a better means of allocating capital as well as providing greater market liquidity. They went further to argue that convergence to IFRS is likely to enhance financial reporting by so doing, multinational companies will have a cost advantage and hence there will be no need for companies to report using more than one set of accounting standards.

Thus, Cai and Wong (2010) postulate that a single set of accounting standards with global acceptance will annihilate the need to restate financial statements and also ensure accounting diversity across countries. In this manner, a greater integration of global financial markets and cross-border movement of capital will be enhanced. While Li (2010) proposes that IFRS is a set of standards that are of higher quality than local standards and thus are capable of restricting accounting discretion. This in turn, will reduce financial reporting uncertainty and increase market transparency. Kim and Li (2010) on their own part argued that even if the convergence to IFRS does not improve financial reporting, it is likely that financial information will turn out to be more comparable and thus become more useful to investors as well as lower estimation risk and reduce information asymmetries. On the contrary, the opponent of convergence to IFRS based their argument on the fact that inconsistency in the implementation of the standards and poor enforcement mechanism may lower financial reporting quality as well as lead to greater opportunistic managerial discretion. They went further to argue that adoption of IFRS is just a single factor among numerous factors such as institutional, legal and cultural background that shapes the quality of financial reporting across countries (Jermakowicz \& Gornik-Tomaszewski, 2006).

Sunder (2007), argued that global adoption of IFRS may not adequately reflect regional variations across countries. Similarly, IFRS does not adequately accommodate countries political and economic differences as such mandatory adoption of IFRS may not actually increase comparability. While, Daske, Hail, Leuz and Verdi (2008) noticed the limited role of IFRS adoption in determining reporting quality and thus suggest that proper implementation and enforcement is required in order to ensure a positive economic consequences. Ahmed, Neel and Wang (2013) points out that the introduction of IFRS has resulted in lowering the financial reporting quality. The trio attributes this to lack of implementation guidance when applying principles based standards. Horton, Serafeim and Serafeim (2013) on their own part observed 
that the adoption of IFRS has not reduced the level of earnings management. In effect, the prevalence of earnings management has even increased over time. Therefore, they are uncertain on the fact that changes in accounting standards per se could lead to changes in the quality of financial reporting numbers.

In spite of the argument against global convergence to IFRS, certainly the adoption of the standards will reduce the cost of doing business across countries by reducing the need for supplementary information, facilitate easy access to global capital, increase the practice of transparency and public accountability, enhance the understanding and the ability to generate value from strategic processes and synergies as well as facilitate the encouragement and attraction of foreign investors (The Nation, 2013). Hence, convergence to IFRS will equally help in maintaining credibility of financial reporting for a wide range of users thereby increasing efficiency in financial reporting (Obazee, 2008). Essentially, the pace with which IFRS adoption is going, it is now becoming a global phenomenon with a good number of countries in Australia, Asia, Middle East and Africa adopting IFRS as a yardstick of preparing their financial reports. Hence, the adoption of IFRS across nations is seen as a means of increasing cross-border comparability, reporting transparency, increase capital flow, improved capital market efficiency as well as minimizes information asymmetry (Ball, 2006).

\section{Methodology}

This study seeks to assess the achievements on adopting IFRS in Nigeria and is predominantly based on review of various journals, research papers, newspaper articles, periodicals and other documentary materials of professional accounting bodies as well as conferences, seminars and workshop papers.

\section{Nigeria's Journey towards IFRS Implementation}

As stated in the introduction, the process of IFRS adoption in Nigeria began in December, 2010 when the nation's Federal Executive Council approved the adoption of the global standard; the FRCN design a roadmap that serves as a guiding principle in the implementation process. Also, the Nigerian Securities and Exchange Commission (SEC) and Central Bank of Nigeria (CBN) issue guidance compliance circulars to ensure full implementation of IFRS in Nigeria. (Adeyemo, 2013). However, the moves towards implementation of the first phase based on the roadmap started in earnest, the CBN as one of the main regulators initiate a partial adoption of the IFRS in Nigerian banking system, this move according to CBN was an attempt to integrate the banking system into the global best practices in financial reporting and disclosure, and a step toward enhancing market discipline and reduce uncertainties which limit the risk of unwarranted contagion (Oduware, 2012). Similarly, the National Insurance Commission (NAICOM) in its quest to take a leading role among other regulators issued a guideline at the end of year 2010 outlining the returns expected by insurance companies in 2011 and also organized series of workshops for insurance companies' personnel to facilitate effective transition. In the same vain, NAICOM also unveiled a roadmap to guide insurance companies' conversion to IFRS which took off on Jan 1, 2012. According to the roadmap, all insurance and reinsurance companies classified under public interest entities are expected to commence their transition from January 1,2011, while the insurance brokers classified under other public interest entities will take their turn in 2012 (Anaesoronye, 2012).

Moreover, the Federal Inland Revenue Service (FIRS) in its capacity as a member of the roadmap implementation committee and the body responsible for assessing and collecting tax return issued a draft information circular in October, 2012 on the Tax Implication of the adoption of the IFRS (Oduware, 2012). Despite all the efforts made by the relevant stakeholders, most firms are still far behind in their implementation drive. Specifically, challenges were encountered by listed entities in meeting their regulatory periodic filing obligations with the Nigerian Stock Exchange (NSE) for fiscal 2012 audited accounts and 2013 Interim Accounts. In response to this obstacle confronted by the listed entities, The NSE verified on March 28, 2013 it willingness to grant all listed entities a thirty days (30) extension of time from the due date of the required periodic financial statements. The extension is intended to offer businesses and advisors a fresh assurance on the adoption of IFRS and also increased levels of regulatory approvals. Therefore, during the extension period, the Exchange will refrain from imposing any financial or disclosure penalties on business entities that fail to comply (Nnorom, 2013). While the FRCN in its drive to ensure compliance by companies in line with the recent adoption of IFRS; is planning to impose sanctions on organizations that fail to tender their financial statement within the stipulated period by withdrawing their licenses and also placing their names on the website for non-compliance to statutory 
laws (Ogunlade, 2013). Furthermore, the second phase of the implementation process is channeled on Other Public Interest Entities that are under statutory obligation to adopt IFRS by December 31, 2013.With barely few months to the deadline, one will be prompted to ask what is level of preparedness of these entities in the implementation drive. What are the enforcement mechanisms put in place by relevant stakeholders to achieve the proposed target? What are the lesson learn from the implementation of the initial phase and what are the corrective measures put in place to ensure smooth and timely implementation of the remaining phases.

In order to tackle the aforementioned questions, The Federation Account Allocation Committee (FAAC) in its effort to complement the timely adoption and implementation of the second phase of IFRS adoption in Nigeria, inaugurated a sub-committee on June 13, 2011; the committee is saddled with the responsibility of enhancing a speedy and smooth implementation of the new standard. The committee has been going round organizing series of sensitization workshops in the six geopolitical zones of the country, enlightening the relevant stakeholders on the need and benefit of having a unified accounting standard that will provide a single set of accounting system within the three tiers of government (Udo, 2013). Similarly, the office of the Accountant-General of the federation and that of FRCN in May 2012, organized a stakeholders' workshop and thus resolve to collaborate in promoting the use of the widely advocated International Public Sector Accounting Standards (IPSAS) in public entities, this is perceived by the duo as a means of strengthening accountability and transparency of financial report in public sector, improve service delivery, facilitate Public-Private Partnership (PPP), enhance easy and peer review of financial information between the three tier of governments as well as building more confidence in the eyes of international donor agencies (Oduware, 2012). More so, the third and the final phase of IFRS implementation in Nigeria are geared towards Small and Medium Enterprises (SME) whom are statutorily required to issue their financial reports based on IFRS's framework at the end of December 2014. This phase is assumed to be the most critical stage in the implementation drive considering the size and number of SME's in Nigeria (Aruwa, 2004). Therefore, to ensure smooth transition to IFRS, Small and Medium Enterprises Development Agency (SMEDAN) which is the body established to promote the development of micro, small and medium enterprises sector in Nigeria is collaborating with Association of Chartered Certified Accountants (ACCA) to educate and enlighten relevant stakeholders in this subsector on the need and significance of adopting the widely acclaimed IFRS in preparing their financial statement (Azeez, 2013).

In similar manner, the CBN as a regulator of SME's has developed a general implementation framework for SME's ahead of January,2014.This framework is to ensure that appropriate changes and restructuring are effected on systems and processes for effective transition (The Nation, 2013).Whilst The FRCN on its own capacity as the mastermind of IFRS adoption in Nigeria enjoined the SME's to commence the processes and activities of entrenching their accounts towards adoption of IFRS by January 1, 2014. FRCN mandated the SME's to adhere strictly to the directive and ensure full compliance as delineated in the roadmap. Consequently, FRCN charged the companies to invest massively on IFRS issues and intricacies as IFRS required requisite knowledge and skills. Also, as part of bridging the knowledge gap, FRCN had established an IFRS academy in the country and may most probably called for the inclusion of IFRS study in the curriculum of higher institutions to facilitate the understanding of IFRS skills and knowledge (Izuora, 2013).

Challenges of Adopting IFRS in Nigeria: The adoption of IFRS is known to be a Herculean task owing to the fact that several challenges are often encountered in the cause of implementation. These challenges are not peculiar to Nigeria but are common in most countries that are in the process of adopting the global standard, although there are some unique challenges that are specific to particular countries (Robyn and Graeme, 2009). For instance, Iyoha and Faboyede (2011) noticed that ethical environment and the ability of companies to protect their experienced employees from being taken over by their counterpart is among the main challenges faced by companies in Nigeria. Other significant challenges include the requirement of IFRS for a more broaden financial reporting which will invariably result in added costs for companies. Similarly, the regulatory requirement to amend the existing tax laws to effect the changes in line with the new standard is also a point to consider. Additionally, the level of education and experience, level of awareness, Weak enforcement and compliance mechanism are also instrumental to the successful implementation of the process, these challenges are broadly discussed as follows:

1) Implementation Costs: The first time adoption of IFRS framework is perceived by most entities as costly, these costs usually relate to consultants' costs, costs of training personnel and costs of adjusting 
the existing accounting system to effect the change (Ionascu, Olimid \& Calu, 2007). This challenge has made management of most companies to be reluctant in embracing the change which invariably resulted in mellow attitude by staff on IFRS issues and therefore, contributed immensely to retardation in IFRS conversion process in Nigeria (Oduware, 2012).

2) Amendment of Existing Laws: The adoption of IFRS in Nigeria has resulted in the amendment of different tax laws as well as numerous tax considerations (Ernst \& Young, 2013). These tax considerations are complex and therefore arise from the computation of deferred tax attributed to IFRS adjustments effect. With the adoption of IFRS, the basis for computation of deferred tax varies from how it was previously computed during Statement of Accounting Standards (SAS) regime. IFRS involves the use of the balance sheet liability method and therefore focused on temporary differences, whilst SAS dwells on income statement method and thus focus on timing differences. In this respect, the use of the balance sheet liability method will demand full deferred tax provision which is more complex when compared to the income statement method (Oduware, 2012). Hence, these issues had been a source of concern for Federal Inland Revenue Service (FIRS) in Nigeria.

3) Inadequate Technical Capacity: The implementation of the IFRS framework demands sufficient technical capacity within the various stakeholders including the preparers, auditors, regulatory authorities and users of financial reports (Madawaki, 2012). Therefore, one of the main challenges of implementing IFRS in Nigeria is a shortage of Accountants and Auditors that are skilled in IFRS reporting. According to Oduware (2012), in most entities, an average accountant does not have the knowledge of advanced financial management techniques which includes forecasting, impairment analysis and financial instruments. Hence, this had been a foremost challenge on IFRS implementation process in Nigeria.

4) Level of Awareness: The process of transition to IFRS and its implication for preparers and other stakeholders including regulators and educators need to be effectively coordinated and communicated (NASB, 2010). But despite effort made by different stakeholders and regulators through organizing series of sensitization workshop and other means of reaching out to targeted audience across the country, the level of awareness among companies' executives is relatively low, managers of most entities tends to look at the transition process as a means of increasing cost of reporting ignoring the benefit to be derived from the entire process.

5) Level of Education and Experience: The implementation of IFRS is strategic and a critical decision that requires a high level of education, expertise and competence to enable users to understand, interpret and effectively use the standards in financial reporting (Adeyemo, 2013). Therefore, lower level of education and weak experience in IFRS reporting in Nigeria has become a barrier to successful implementation of IFRS framework. Similarly, considering the limited time frame given for the transition, integrating IFRS syllabus into accounting education in higher institution's curricula and coordinating such programs within professional institutions' requirement and regulations is also a foremost challenge to smooth implementation of IFRS in Nigeria.

6) Level of Technology: Technology has a major effect on IFRS implementation. Therefore, Information Technology (IT) is definitely a key factor in IFRS transition process considering the important role played by Enterprise Resource Planning (ERP) systems in companies operational, accounting and reporting processes (Uzor, 2011). Therefore, for companies to achieve a seamless conversion to IFRS; there is a need to be familiar with specific IT challenges and issues confronting their organization. In Nigeria, companies give less emphasis on technology which is invariably affecting the pace with which implementation of IFRS is going on in the country.

7) Improper Planning: The underestimation of the complexities involves in implementing IFRS by companies' and expertise's is among the challenges of IFRS transition in Nigeria. According to KPMG report 2012, companies' executives sometimes underestimate how difficult transition to IFRS will be; they assume is something that can be done within some few days or weeks. But to their surprise it turns out to be a process that takes an intensive time as it affects people, processes and systems.

8) Transition Management: One of the challenges impeding IFRS implementation in Nigeria is the change which reporting entities are obliged to effect in order to operate the new regime. This challenge includes that of coping with additional data elements as well as managing the task of transition into a new process of reporting. Similarly, the implementation also requires at the initial stage a simultaneous 
comparative reporting based on both the existing and also the new standard and thus understanding the differences between the two.

9) Inadequate Private Sector Participation: The onerous of implementing IFRS to a large extent depends on the involvement of private sector operators, In Nigerian case, the IFRS roadmap implementation committee constituted by NASB has less representation of major players in the private sector which is contributing to the sluggish transition process in the country.

10) Enforcement Mechanism: The transition to IFRS has a serious implication for regulators; this requires extensive use of judgments and assumptions that need to be considered by relevant regulatory authorities (Ehijeagbon, 2010). In Nigeria, the legal process is really slow; this discourages regulators from taking legal recourse as regards enforcing compliance with accounting and financial reporting requirements. This state of affairs is impairing on the ongoing IFRS implementation process in Nigeria.

Counter Measure for Effective Adoption of IFRS: The transition from the existing local gap to IFRS represent a major change in organizations' processes, these changes are not limited to organizations' financial results, but it also involves changes in their business processes, internal systems, external communication and performance management. Therefore, the implementation process will impact on all facets of an organization as well as the people involved. As such, it requires intensive planning and coordination across functional lines such as accounting, treasury, tax, information technology and Human resources (Aladenusi, 2012). Based on the aforesaid, the concern stakeholders in the IFRS implementation process in Nigeria need to consider the under listed points in order to tackle the current challenges and also ensure smooth and successful transition process in the remaining phases.

1) Increasing Private Sector Participation: As stated above, the IFRS roadmap implementation committee is deficient in private sector representation, it is therefore expedient for NASB to review and restructure the existing committee with the aim of engaging more operators in the private sector whose valuable contribution will ensure a dynamic and viable roadmap that will be able to resist major challenges ahead.

2) Incentives for Motivation: In order to achieve maximum support of the business community in relation to IFRS implementation especially SME's, government at all levels need to offer some kind of incentives to business entities such as reducing their tax burdens, providing them with an enabling environment to strive and grow, provide them with more access to capital. In addition, regulatory authorities need to take up their roles and thus formulate an all-inclusive IFRS with the businesses by way of utilizing the present operating conditions with the view to improve and recommend a suitable way of enriching the existing financial reporting standards.

3) Enlightenment on Retrospect Nature of IFRS: The FRCN and other relevant regulatory bodies need to inform the operators of IFRS that the standard has provided a soft-landing for first-time adopters on retrospective application of the standard with the view to pre-empt the cost of IFRS adoption to outweigh its benefits and also in certain situations where application of a particular aspect of the standard prove impracticable.

4) Raising Awareness: For the current ongoing IFRS transition process in Nigerian to be successful; a holistic approach in level of awareness should be adopted. Specifically, massive sensitization and communication programs should be undertaken. Thus, countrywide intensive capacity building programs should be organized in order to facilitate and sustain the adoption process. Fundamentally, raising awareness among stakeholders on potential benefits of adopting IFRS and its subsequent impact on companies' financial performance will enhance the implementation process.

5) Project Management: The implementation of the IFRS framework honestly demands an extensive paradigm shift by all relevant stakeholders which can be achieved through a well-conceived and executed change in management programs (Access bank, 2010). Therefore, for the ongoing Nigeria's IFRS implementation to be successful, a project management office should be established with the view to develop programs that will sustain and enhance effective implementation of the scheme.

6) IT Issues: Business entities should initially scrutinize and understand the technical accounting disparity between their existing reporting requirement and that of IFRS as it relates to their own 
operations with the view to identify the basic impact of IT and how to strategically design a future state system. Consequently, organizations should engage reputable IT vendors to address their IT challenges. In the same vain, business entities are enjoined to put in place a functional requirement blueprint that will emanate from an exhaustive gap analysis between the capabilities of their existing IT systems and the required future state systems that will be IFRS inclined.

Integrating IFRS into Educational curriculum: The higher institutions and professional accountancy bodies such as the Institute of Chartered Accountants of Nigeria (ICAN) and the Association of National Accountants of Nigeria (ANAN) should integrate IFRS syllabus into their curriculum to enhance the knowledge of IFRS among students who are believed to be the sustainers of the system in future. Similarly, the professional accountancy bodies need to align their periodic continuing professional education requirements in accordance with IFAC guidelines (Madawaki, 2012). Finally, a committee representing chartered accounting firms should be established to carry out a peer review and also to discuss technical issues affecting the IFRS implementation as well as adopt a common position when it comes to issues bordering on IFRS interpretation.

Amendment of Existing Tax laws: The existing tax laws necessitated abrupt amendments in accordance with the requirements of IFRS in order to ensure a seamless adoption of the standard and reduce the possible areas of conflict. In Nigeria, it is imperative that required amendments should be made to the prevailing laws to effect enforcement of compliance with the IFRS, this will include but not limited to training of staff of FIRS. But where as a result of IFRS adoption a different tax treatment is needed other than what is stipulated in the law, the relevant provisions should be amended with the aim of giving IFRS adoption a full effect and thus provide certainty to ordinary taxpayers.

Effective Evaluation and Planning: The process of conversion to IFRS is much more than just changing from a set of accounting principles to another or a mere technical exercise. Therefore, entities executives need to be conversant with the bigger picture of their organization in order to fully understand how the proposed IFRS conversion will impact on relevant facets of their organization and thus make adequate planning in order to achieve a seamless implementation process. Thus, the planning process will generally include issues bordering on accounting, taxation, statutory reporting, internal processes and organizational issues. Hence, an early commencement of IFRS conversion process will put business entities in a position to be able to report reliably under the IFRS as well as meet up with the stipulated dateline as enriched in the implementation roadmap.

Capacity Building: It had been acknowledged that the transition to IFRS in Nigeria will require all major stakeholders including regulators and companies to work in unison to address common challenges and thus highlight similar opportunities with the view to achieve a smooth IFRS implementation process (standard chartered bank, 2011). In this respect, regulators and the business entities are required to intensify their efforts in training and building staff capacity in the course of adopting IFRS. Specifically, a new approach should be adopted which will involve a mix of classroom trainings, interactive sessions and other external workshops with the view to acquire a broader experience given the enormity of the changes and technicalities that will arise as a result of adopting IFRS.

\section{Conclusion}

Overall, the objective of this study is to assess the achievements recorded so far, challenges being encountered, and measure taken in order to ensure a smooth and successful implementation of the three phases of IFRS implementation in Nigeria. Based on aforesaid, the researcher was able to access the level of implementation of the initial phase which is targeted on Banks and Other Significant Public Listed Entities who are expected to render their 2012 financial report using IFRS framework, likewise their level of preparedness and compliance as well. Finding from the study reveals that most publicly quoted companies listed on the Nigerian stock exchange (NSE) were still far behind in their implementation drive. Specifically, challenges were encountered by listed entities in meeting their regulatory periodic filing obligations with the Exchange for fiscal 2012 Audited Accounts and 2013 Interim Accounts (Nnorom, 2013). This delay is attributed to several factors which ranges from challenge of amending the existing tax laws to effect the changes in line with the new standards, the level of education and experience, level of awareness, Weak enforcement and compliance mechanism, inadequate technical capacity, improper planning on the part of management as well as inadequate private sector participation. Consequently, the researcher suggest some counter measure to forestall these challenges 
which includes the need to engage more private sector participants in the roadmap implementation committee, the need to offer some kind of incentives to business entities to reduce their initial implementation costs, a different and holistic approach to creating awareness among the relevant stakeholders, the need to intensify efforts in training and building staff capacity, the IT issues, the need to integrate IFRS syllabus in the curriculum of higher institutions as well as the essence of early preparation and adequate planning by companies.

In summary, it is realistic to believe that conversion to IFRS is certainly a herculean task and thus a major challenge which requires a great deal of decisiveness and commitment. On this backdrop, Nigerian business entities should view the conversion to IFRS as a challenge and also an opportunity to standardize their financial reporting process and to align it with global best practices given the enormous benefits to be derived from adopting the standards. Fundamentally, the adoption of a high quality set of accounting standards will improve accounting information and also facilitate trade and other investment opportunities and in turn, foster comparability, transparency and reduce information asymmetries across countries. Hence, the IFRS ship is already sailing around the world as a single set of high quality accounting standards with rapid global acceptance.

\section{References}

Access Bank. (2011). A continuing commitment to Nigeria's economic growth and development, A final communiqué organized by Access Bank in Abuja, July,19 \& 20.

Adeyemo, K. A. (2013). Mandatory Adoption of International Financial Reporting Standards (IFRS) in Nigeria: The Unresolved Institutional Question.

Ahmed, A. S., Neel, M. \& Wang, D. (2013). Does mandatory adoption of IFRS improve accounting quality? Preliminary evidence, Contemporary Accounting Research.

Aladenusi, T. (2012). How adoption of IFRS will impact its systems in Nigeria, Business day Newspaper, June, 18

Anaesoronye, M. (2012). Insurers see compliance in face of NSE deadlines, Business day newspapers of January, 31

Armstrong, C. S., Barth, M. E., Jagolinzer, A. D. \& Riedl, E. J. (2010). Market reaction to the adoption of IFRS in Europe. The accounting review, 85(1), 31-61.

Aruwa, S. A. S. (2004). Financing options for small and medium scale enterprises in Nigeria. The Nigerian Journal of Accounting and Research, Department of Accounting, Ahmadu Bello University, Zaria $1(2)$.

Azeez, K. (2013). ACCA partners SMEDAN on IFRS education for SMEs National Mirror march, 1. http://nationalmirroronline.net/new/acca-partners-smedan-on-ifrs-education-for-smes/

Ball, R. (2006). International Financial Reporting Standards (IFRS): pros and cons for investors. Accounting and Business Research, 36, 5-27.

Cai, F. \& Wong, H. (2010). The effect of IFRS adoption on global market integration. International Business and Economics Research Journal, 9(10), 25-34.

Daske, H., Hail, L., Leuz, C. \& Verdi, R. (2008). Mandatory IFRS reporting around the world: Early evidence on the economic consequences. Journal of Accounting Research, 46(5), 1085-1142.

Ehijeagbon, A. A. (2010). The Adoption and Implementation of International Financial Accounting Reporting Standards (IFRSS): Evaluation of the Roles of Key Stakeholders in Nigeria. AAU JMS, $1(1), 147-158$.

Ernst \& Young. (2013). Nigerian tax authorities issue guidiance on tax implications of adoption of IFRS, Tax alert June, 6 .

Epstein, B. J. \& Jermakowicz, E. K. (2010). WILEY Interpretation and Application of International Financial Reporting Standards 2010. Wiley.

Hail, L., Leuz, C. \& Wysocki, P. (2010). Global accounting convergence and the potential adoption of IFRS by the United States: an analysis of Economic and policy factors .Working paper. Available: http://ssrn.com/abstract=1357331S. Accessed on 10th July2010.

Horton, J., Serafeim, G. \& Serafeim, I. (2013). Does mandatory IFRS adoption improve the information environment? Contemporary Accounting Research, 30,388-423.

Ionascu I., Olimid L. \& Calu, D. A. (2007). An Empirical Evaluation of the Costs of Harmonizing Romanian Accounting with International Regulations (EU Directives and IAS/IFRS). Accounting in Europe, $4(2), 169-206$

Iyoha, F. O. \& Faboyede, S. O. (2011). Adopting international financial reporting standards (IFRS) - a focus on Nigeria. International journal of research in commerce \& management, 2(1), 35-40. 
Izuora, C. (2013). IFRS for SMEs Non-Negotiable, leadership newspapers march, 9.

Jermakowicz, E. K. \& Gornik-Tomaszewski, S. (2006). Implementing IFRS from the perspective of EU publicly traded companies. Journal of International Accounting, Auditing and Taxation, 15(2), 170-196.

Kim, Y. \& Li, S. (2010). Mandatory IFRS adoption and intra-industry information transfers. Document de travail, Leavey School of Business, Université de Santa Clara.

Li, S. (2010). Does mandatory adoption of international financial reporting standards in the European union reduce the cost of equity capital? Accounting Review, 85, 607-636.

Larson, R. K. \& Street, D. L. (2004). Convergence with IFRS in an expanding Europe: progress and obstacles identified by large accounting firms' survey. Journal of International Accounting, Auditing and Taxation, 13(2), 89-119.

Madawaki, A. (2012). Adoption of International Financial Reporting Standards in developing countries: the case of Nigeria. International Journal of Business and management, 7(3), 152.

Nigerian Accounting Standard Board. (2010). Report of roadmap committee on the Adoption of International Financial Reporting Standards (IFRS) in Nigeria.

Nnorom, N. (2013). NSE extends deadline for financial statements' Submission, Vanguard Newspaper, March 29, 2013See more at: http://www.vanguardngr.com/2013/03/nse-extends-deadline-forfinancial-statements-submission/?utm

Nyor, T. (2012). Challenges of Converging to IFRS in Nigeria. International Journal of Business and Information Technology, 2(2).

Obazee, J.(2008). Towards actualizing the reliability of financial reporting in Nigeria: The role of the Nigerian accounting standards board.The Nigerian Accountant, 41(4), 19-21.

Oduware, U. (2012). IFRS Adoption in Nigeria \& Optimizing the Gains of Global Investment Climate Retrieved from www.wecadeloitte.com/extranet/ifrsacademy/display/pges on Tuesday August 6,2013

Ogunlade, A. (2013). Federal government to prosecute firms with poor financial records, the nation's newspaper, September, 8.

Prather-Kinsey, J. (2006). Developing countries converging with developed-country accounting standards: Evidence from South Africa and Mexico. The International Journal of Accounting, 41(2), 141-162.

Robyn, P. \& Graeme, D. (2009). Implementing IFRS in local government: value adding or additional pain? Qualitative Research in Accounting \& Management, 6(3), 180-196.

Standard Chatered Bank. (2011). Standard Chatered and Regulators help to create awareness for IFRS adoption in the banking sector, A 5 day training workshop to bring to the forefront key implementation issues arising from Nigeria's adoption of IFRS, September.

Sunder, S. (2007). Adverse Effects of Accounting Uniformity on Practice, Education, and Research Working paper.Available at SSRN:http://ssrn.com/abstract=1028517.

Tesfu, F. F. (2012). The Adoption of International Financial Reporting Standards (IFRS) in Ethiopia: Benefits and Key Challenges (Doctoral dissertation, Addis Ababa University).

The Nation. (2013). CBN set 2014 deadline for SMEs' compliance, the nation newspaper, March 13.

Udo, B. (2013). Nigerian government adopts new public accounts strategy for 2014, Premium time's newspaper, September, 9. http://premiumtimesng.com/business/144924-nigerian-governmentadopts-new-public-accounts-strategy-2014-budget.html

United Nations Conference On Trade, Development. Intergovernmental Working Group of Experts on International Standards of Accounting, \& Reporting. (2008). Practical Implementation of International Financial Reporting Standards: Lessons Learned: Country Case Studies on IFRS. United Nations Publications.

Uzor, B. (2011) Experts warns against neglect of technology in IFRS conversion, Business day newspaper, May, 24 http://www.businessdayonline.com/NG/index.php/tech/78-computing/21911-expertwarns-against-neglect-of-technology-in-ifrs-conversion

Zeghal, D. \& Mhedhbi, K. (2006). An analysis of the factors affecting the adoption of international accounting standards by developing countries. Published by University of Illinois, 2006. 